\title{
EXPLORING ACADEMIC AND OCCUPATIONAL INTEREST APTITUDES AS PREDICTORS OF ACADEMIC PERSISTENCE: BASIS FOR ATTRITION INTERVENTION PROGRAM
}

\author{
Rachelle A. Bersamin \\ Professor, PhD, Ateneo de Davao University and University of the Philippines Mindanao, Davao \\ City, Philippines, rabersamin1@up.edu.ph
}

\begin{abstract}
This study explored the academic aptitudes (AA) and occupational interest aptitudes (OIA) as predictors of first-year-to-third-year academic persistence (AP) of the 2,836 first-year college students using purposive sampling and predictive-correlational design. Results of the discriminant function analysis showed that academic persistence was significantly predicted by verbal (AAv) and non-verbal (AAnv academic aptitudes (Wilks' $\lambda=.952, \mathrm{X} 2=140.47 ; \mathrm{p}<.05=.001$ ). The discriminant function accurately classified $63.8 \%$ of the group membership and explained $4.84 \%$ of the variance. Academic persistence was also significantly predicted by business-detail, physical-performing, scientific, mechanical, and nature occupational interest aptitudes (Wilks' $\lambda=.973 ; \mathrm{X} 2=77.624 ; \mathrm{p}<.05=.001$ ) with $60.5 \%$ accuracy rate and explained $2.72 \%$ of the variance. Furthermore, in a combined analysis of academic aptitudes and occupational interest aptitudes, verbal, nonverbal, business-detail, physical-performing, scientific, mechanical, and natural aptitudes significantly predicted academic persistence (Wilks' $\lambda=.939 ; \mathrm{X} 2=177.44 ; \mathrm{p}<.05=001$ ). Discriminant function accurately classified $65.6 \%$ and accounted for $6.10 \%$ of the predicted group membership. In addition, three terms emerged in the content analysis to have contributed to academic persistence: a) competence and motivation, b) attitude and effort c) support and involvement. This study has implications in counseling and student attrition intervention programs in higher education.
\end{abstract}

Keywords: academic aptitudes, occupational interest aptitudes, academic persistence, attrition intervention

\section{INTRODUCTION}

Across the globe, there are only two possibilities that a student may come across as he or she enters university or college, that is, to succeed or fail in adapting to campus tasks. The reality that some students succeed while a considerable number failed to integrate into higher learning institutions makes academic persistence one of the most widely investigated areas of research in higher education (Metz, 2004). For over 70 years (Braxton, 2002), academic persistence has been gravitating scholars, educators, school administrators, and policymakers mainly because of its economic and socio-psychological value.

Today, a good number of comprehensive studies and models are already available in the literature. However, understanding the dynamic of academic persistence is complex. Academic and non-academic variables are intricately involved (Goradia \& Bugarcic, 2019; Stewart, Lim \& Kim, 2015; Navarro et al., 2019). At present there is no single best predictor for this phenomenon. Moreover, though we have already gained a broad understanding on the process of student persistence; accordingly, such gains have not been translated into gains in students' persistence (Tinto \& Pusher, (2006). For example, Carey (as cited in Tinto \& Pusser, 2006) concluded that college completion rates in the United States had not changed appreciably 
in the past 20 years, if not longer. The National Center for Education Statistics (NCES) also reported a 6year graduation rate weighted average of $57 \%$ (Horn, 2006). Recently, the American Enterprise Institute (AEI) reported that, on average, four-year colleges graduate fewer than 60 percent of their freshmen within six years and that in many institutions, graduation rates are far worse (Hess, Schneider, Carey, \& Kelly, 2009).

The student attrition rate or college completion rate mirrors academic persistence. In the Philippines, data indicates that much is needed to be done regarding the college completion rate. As Wallace (2004) reported, the dropout rate in college is as high as $73 \%$. The report also revealed that for every 100 children, only 67 finish primary school, 45 finish secondary school, and only seven are able to finish college. According to the Commission of Higher Education (CHED) of the Philippines, the dropout rate among college students has reached 83.7 percent, which indicates that annually as high as 2.13 million college students drop out from school while only around 500,000 finish college (Manila Bulletin, 2012).

A high attrition rate or low completion rate is a cause of concern for many private universities because it means financial drawbacks for the institution and its reputation. Moreover, the quality of education that a university delivers is at stake when a sizeable number of its students leave school sooner than expected.

One of the offices that helps students adjust to campus life in college is the guidance office through its academic and psychoeducational services. However, attrition itself impedes the successful implementation of its program because, in most part, a student can avail of the program at the first level but may not be able in the next because the student had already dropped out, changed course major, or transferred to other schools.

Furthermore, specific guidance services such as psychological testing mainly aim to help students discover one's scholastic abilities, academic aptitudes, personality traits, and interests. While this activity helps make campus life adjustments easier for students, it is not primarily designed to identify students at risk of dropping out of school or determine academic persistence. Given the potential of this activity to help determine students at risk and further promote academic persistence, this study explores the extent to which psychological variables such as academic aptitudes and occupational interest aptitudes predict academic persistence.

\subsection{Theoretical Framework}

The theories of Tinto (as cited in Braxton, 2002) and Holland (as cited in Hogan and Blake, 1999) provide the foundation for utilizing academic aptitudes and occupational aptitudes as predictor variables in this study. Both theories explicate how academic aptitudes and occupational interest aptitudes influence the dynamics behind the academic persistence process.

Tinto's student departure theory states that students enter college with various individual characteristics, which play significant roles in the college departure process. These individual characteristics include family background factors, individual attributes, and pre-college schooling experiences. Accordingly, these variables influence students' integration and commitment processes, which are antecedents of students' decision to be persistent or not in school. One of the individual characteristics that has been empirically tested to predict future academic outcomes is students' academic aptitudes, especially the verbal and nonverbal domains (Macklem, 1990). Hence, this study presupposes that individual characteristics such as academic aptitudes (verbal, non-verbal) are predictive of academic persistence.

On the other hand, the person-environment-fit theory of Holland (as cited in Hogan \& Blake, 1999) assumes that certain people tend to fall into certain personality classifications that commensurate to specific environment type (as cited in Feldman, Smart, \& Ethington, 1999; Spokane, Luchetta, \& Richwine, 2002). Congruence or non-congruence therein determines one's decision to stay in a task or depart. Academic persistence is then viewed in this theory to result when one's occupational interest matches one's environment (e.g., college major). On the other hand, student departure is seen as a consequence of the misfit between occupational interest and the environment. On the one hand, this provides the structure for the classifications of various occupational interests involved in this study. Guided by this theory, this study hypothesized that a certain group of students are likely to display at least one dominant occupational interest among the various classifications or a composite thereof. In a similar thread, each group is likely to yield a unique set of occupational interests predictive of academic persistence.

Both Tinto and Holland's theories provide the rational organization of the variables in this study with which academic persistence can be examined. Moreover, studies conducted by Tracy and Robins (2006) and Burton and Ramist (2001) independently lend support to the academic aptitudes and occupational interest 
aptitudes as predictors of academic persistence.

Based on this framework, this study hypothesized academic aptitudes and occupational interest aptitudes alone and in combination, predict first-year-to-thirds-year academic persistence among freshmen students enrolled in the first semester of SY 2008-2009.

\subsection{Conceptual Framework}

This study's independent or predictor variables were academic aptitude (AA) and occupational interest aptitude (OIA). Academic aptitudes were measured using verbal aptitude, including general information, mental alertness, comprehension of relations, and non-verbal, including spatial relation, comprehension of physical relations, and graphic relations subscales. On the other hand, occupational interest aptitudes were measured using twelve subscales as indicators: artistic, scientific, nature, protective, mechanical, industrial, business detail, selling, accommodating, humanitarian, leading-influencing, and physical performing. The dependent or criterion variable, academic persistence, is measured through its dichotomous indicators: persistent and non-persistent. Independently and in combination the academic aptitudes and occupational interest aptitudes were hypothesized in this study to predict academic persistence. Finally, to further enrich this study's findings, a follow-up discussion among persistent students to explore some of the reasons contributing to their persistence in college was conducted.

\subsection{Statement of the Problem}

The purpose of this study is to explore the extent by which academic aptitudes scores and occupational interest aptitude scores independently or in combination, predict first-year-to-third-year academic persistence among first-year students' college students enrolled in 2008-2009 in one of the universities in Davao City.

Specifically, this study sought to answer the following questions:

1. How well do academic aptitudes predict academic persistence?

2. How well do occupational interest aptitudes predict academic persistence?

3. How well do academic aptitudes and occupational interest aptitudes, in combination, predict academic persistence?

4. What other factors have contributed to students' academic persistence?

\section{METHOD}

\subsection{Design}

This study employed a predictive-correlational research design. This study used two predictor variables: academic aptitudes and occupational interest aptitudes, and one criterion variable, academic persistence. Academic persistence is a dichotomous variable defined as persistent or non-persistent. To determine first year-to-third-year academic persistence, a span of two school years was allowed to pass. The first-year students of 2008-2009 were expected to be in the $3^{\text {rd }}$ year level in SY 2010-2011. Those who remained on the list after two years were categorized as persistent, and those who were not, non-persistent.

\subsection{Participants}

There were 2,836 or $58 \%$ of the 4,866 population involved this study. Participants were taken from the different colleges of a well-known university in Mindanao with the following distribution: 791 (51\%) business administrations, $276(55 \%)$ criminology; $544(64 \%)$ arts and sciences, $395(64 \%)$ accountancy, $185(68 \%)$ education, 391 (51\%), 391 (51\%) engineering and architecture, and $254(82 \%)$ nursing. Using purposive sampling technique, all first-year students from different colleges who were able to take the AAT \& OASIS-2 for the first semester of SY 2008-2009 were taken as respondents of this study.

\subsection{Measures}

To measure the predictor variables of this study, standardized psychological tests were employed. The Occupational Aptitude Survey and Interest Schedule (OASIS-2) by Parker (1991) was used to measure the students' occupational interest aptitude. The Academic Aptitude Test (AAT) by Kobal, Kunze, and Wrightstone (1984) was used to measure the students' verbal and non-verbal academic aptitudes.

\subsubsection{Academic Aptitude Test}

The Academic Aptitude Test (AAT) is composed of verbal and von-verbal aptitudes. The non-verbal aptitude 
test is designed to aid in predicting a student aptitude for an academic career and judging the students' academic abilities. This subtest includes:

1. Spatial relations. This is a test of the ability to match forms of different sizes and shapes. It consists of two parts: first, scrutiny of different groups of forms and matching of the forms for visual and mental reproduction of given patterns; and secondly, judging and determining relative surfaces of different geometric figures.

2. Comprehension of Physical Relations. This subtest offers a variety of illustrations, drawings and comparable figures. It tests the ability to judge and possibly manipulate physical problems of detecting, visualizing, correcting, and reasoning in pictorial and graphic work.

3. Graphic Relations. This is a type of non-verbal classification work that tests at least three different capacities: first, the ability to grasp an abstract problem; secondly, the ability to translate the problem; and third, the ability of association and classification.

The verbal aptitude test is a specialized intelligence test that measures mental abilities and proficiencies that are important in academic work. The test is designed to aid in predicting a student's aptitude for an academic career. This subtest is composed of three subtests:

1. General Information. Items include a wide variety of subjects for academic work and general science.

2. Mental Alertness. This subtest includes sections on comprehension, judgment, and arithmetic reasoning.

3. Comprehension of Relations. This subtest consists of three: selection, analogies, and classification. Mental aptitude such that required for independent judgment tasks, complex association and logical thinking constitutes the contents of this subtest.

\subsubsection{Occupational Aptitude Survey and Interest Schedule}

To measure the occupational interest aptitude of the first-year students, the Occupational Aptitude Survey and Interest Schedule 2nd ed.(OASIS-2) by Parker (1991) was used. This test was developed to assist students in self-exploration, vocational explorations and career development. This instrument intends to help students in educational and career planning. This test is composed of 12 subscales.

1. Artistic (art). This scale measures one's interest in the creative expression of ideas and feelings. This interest may be satisfied by various activities, including writing or editing, performing in music, drama or dance, painting or sculpturing, or modeling clothes.

2. Scientific (sci). A high score in this area indicates an interest in doing scientific research and developing theories and scientific applications. This interest may be satisfied by working with scientific equipment in a laboratory; by exploring new medical treatments to improve humans and animals; by developing new knowledge in mathematics or physics; or discovering new facts about the earth and universe.

3. Nature (nat). This scale measures one's interest in working with plants and animals in an outdoor setting. One may satisfy this interest by working in farming, forestry, and fishing.

4. Protective (pro). A high score in this area suggests an interest in using legal authority to protect both people and property.

5. Mechanical (mec). A high score on this scale indicates an interest in applying mechanical principles to practical situations involving tools and machines.

6. Industrial (ind). This scale measures one's interest in repetitive, regular work activities in a factory setting.

7. Business Detail (bus). A high score in this area suggests that one may enjoy office work.

8. Selling (sel). A high score on this scale indicates an interest in providing information about a product and persuading others of its value and desirability.

9. Accommodating (acc). This scale measures one's interest in providing services for the convenience and comfort of others.

10. Humanitarian (hum). A high score on this scale indicates an interest in helping people with problems of a physical, social, emotional, or religious nature.

11.Leading-Influencing (lea). This scale measures one's interest in leading and influencing others by using verbal and numerical abilities.

12. Physical-Performing (phy). High scores in this area show an interest in performing physical activities 
before an audience.

\subsubsection{Academic Persistence}

To measure the dependent/criterion variable, academic persistence, the number and names of students who enrolled in the first semester of SY 2008-2009 and the number and names of students who remained in SY 2010-2011 were generated. Names not found in SY 2010-2011 list were classified as non-persistent while those who remained, persistent.

\section{RESULTS AND DISCUSSION}

\subsection{Academic Aptitudes as Predictor of Academic Persistence}

To determine whether $A A$ subscles ( $A A v$ and $A A n v)$ predict $A P$, a step-wise discriminant function analysis (DFA) was conducted. The AAv and AAnv served as the predictor variables and AP (persistent or nonpersistent) as the criterion variable. Overall analysis on the ability of AAv and AAnv to predict AP revealed one function and it was found significant in predicting group membership (Wilks' $\lambda=.952, X^{2}=140.47 ; p<.05$ $=.001)$. Both $A A v$ and AAnv entered as significant predictors in the analysis. This means that Wilks' $\lambda$ was significant by $F$ test for both $A A v$ (Wilks' $\lambda=.958 ; F=124.33, p<.05=.000$ ) and AAnv (Wilk's $\lambda=.952 ; F=$ $72.004, p<.05=.000)$. The canonical correlation $\left(r^{2}=.220\right)$ indicated that only $4.84 \%$ of the variability in the predicted group membership (persistent, non-persistent) was accounted for by the AAv and AAnv variables.

Moreover, classification results revealed that out of 434 persistent students, 270 or $62 \%$, and 863 or $64.1 \%$ of the 2,401 non-persistent students were correctly predicted. Overall, the created function accurately classified $63.8 \%$ of the students as persistent or non-persistent. Table 1 presents the discriminant function analysis using academic aptitudes as predictors.

Table 1. Discriminant Function Analysis Using Academic Aptitudes as Predictors of Academic Persistence

\begin{tabular}{lllllll}
\hline Academic Aptitudes & Wilks' $\lambda$ & $X^{2}$ & Sig. & Con $r$ & $r^{2}$ & $\begin{array}{l}\text { Accuracy } \\
\text { Rate }\end{array}$ \\
\hline Verbal & & & & & & \\
Non-verbal & 9.52 & 140.467 & .001 & .220 & $4.84 \%$ & $63.80 \%$ \\
\hline
\end{tabular}

Level of significance $=.05$ alpha

These findings are consistent with previous research studies in showing the predictive value of some academic variables in predicting academic persistence (Burton \& Ramist, 2001; Ragosta, Braun, \& Kaplan,1991; Cornwell, Mustand, \& Pary, 2006, Zwick \& Sklar, 2005; Daugherty \& Lane, 1999; French Immekus, Oakes, 2003; Newton, Smith, Moore, \& Magnam, 2007; Newtoon \& Moore, 2009). Results of this study also lend support to previous studies which demonstrated academic variables such as GPA, aptitude, admission test results, and mental ability as predictors of academic persistence (Caison, 2005; Palmer, 2008; Stickney, 2008; Brown, Lent, \& Larkin, 1989; Robertson \& Taylor, 2009; Titus 2004; Allen \& Robins, 2008; and Higgins, 2005). This study's findings also reveal a $63.80 \%$ hit rate for both AAv and AAnv to discriminate persistent and non-persistent. However, these variables only explained $4.84 \%$ of the variance in the predicted group membership (persistent, non-persistent). This suggests that some variables are still unaccounted for that may have contributed to the students' academic persistence. While AAv and AAnv can be used as predictors of academic persistence, it should not be solely relied upon when identifying at-risk students.

\subsection{Occupational Interest Aptitudes as Predictor of Academic Persistence}

To determine whether each of the OIA (art, sci, nat, pro, mec, ind, bus, sel, acc, hum, lea, phy) predict AP, a step-wise DFA was run, overall analysis on the ability of OIA to predict AP revealed one discriminant function. This function was significant in predicting group membership (Wilks' $\lambda=.973 ; X^{2}=77.624 ; p<.05$ $=.001$ ). Moreover, among the twelve OIA subscales, Wilks' $\lambda$ was significant by $F$ test for four subscales only: bus (Wilks' $\lambda=.993 ; \mathrm{F}=19.596, p<.05=.001$ ); phy (Wilks' $\lambda=.983 ; \mathrm{F}=25.053, \mathrm{p}<.05=.001$ ); sci (Wilks' $\lambda=.978 ; \mathrm{F}=20.805, \mathrm{p}<.05=.001$ ); ind (Wilks' $\lambda=.975 ; \mathrm{F}=17.936, p<.05=.001$ ); and acc (Wilks' $\lambda$ $=.973 ; \mathrm{F}=15.732, \mathrm{p}<.05=.001)$. The canonical correlation $\left(r^{2}=.165\right)$ indicated that $2.72 \%$ of variability in predicted group membership (persistent, non-persistent) was accounted for by the variability in those 
subscales. Overall, this function accurately classified $60.5 \%$ of students as persistent or non-persistent. Table 2 shows the overall discriminant function analysis using occupational interest aptitides as predictors of academic persistence.

Table 2. Discriminant Function Analysis Using Occupational Interest Aptitudes as Predictors of Academic Persistence

\begin{tabular}{lllllll}
\hline $\begin{array}{l}\text { Occupational } \\
\text { Interest Aptitudes }\end{array}$ & Wilks' $\lambda$ & $X^{2}$ & Sig. & Con $r$ & $r^{2}$ & $\begin{array}{l}\text { Accuracy } \\
\text { Rate }\end{array}$ \\
\hline Business Detail & & & & & & \\
Physical-Performing & & & & & & \\
Scientific & .973 & 77.624 & .001 & .165 & 2.72 & $60.5 \%$ \\
Industrial & & & & & & \\
Accommodating & & & & & & \\
\hline
\end{tabular}

Level of significance $=.05$ alpha

These findings are consistent with the previous research of Khan et al., (2002). Using four career and personality assessment inventories, findings revealed that personality and vocational interest subscales uniquely contributed to the prediction of freshmen-to-sophomore persistence. This study's findings also lend support to the unique role personality variables play in students' persistence in school (Ridgell \& Lounsbury, 2004; Chamberlain, Catano, and Cunningham, 2005). Specifically, occupational or vocational interest operates through congruence and impacts academic persistence. For example, previous research pointed out that congruence in one's interest and college-major were predictive of academic persistence (Tracy \& Robins, 2006; Allen \& Robins, 2008; Leuwerke, Robbins, Sawyer, \& Holland, 2004). This study also revealed that only a specific set of occupational interest aptitudes subscales entered as predictors in the DFA model. This suggests that certain personality types are seemed disposed to persist through academic challenges. Though OIA proved to be a significant predictor of AP, caution should be made when using as a basis for identifying students at risk. Canonical correlations indicate that other variables unaccounted for may have also contributed to the students/ decision to persist.

\subsection{Academic Aptitudes Occupational Interest Aptitude as Predictors of Academic Persistence}

A stepwise discriminant function analysis was conducted to determine whether the two predictor variables and each of its subscales: the AA (AAv and AAnv) and OIA (art, sci, nat, pro, mec, individual, bus, sel, acc, hum, lea, phy) in combination discriminate better between persistent and non-persistent students than AA or OIA alone. All 2, 836 respondents were included in the analysis. Result displayed that one discriminant function was found significant (Wilks' $\lambda=.939 ; X^{2}=177.44 ; p<.05=001$ ). Altogether, seven subscales emerged as significant predictors. Academic persistence was significant by $A A v$ (Wilks' $\lambda=.958 ; F=122.78$, $\mathrm{p}<.05=.001$ ); AAnv (Wilks' $\lambda=.952 ; \mathrm{F}=71.008, \mathrm{p}<.05=.001$ ); bus (Wilks' $\lambda=.948 ; \mathrm{F}=51.607, \mathrm{p}<.05=$ .001 ); phy (Wilks' $\lambda=.943 ; \mathrm{F}=42.455, \mathrm{p}<.05=.001$ ); sci (Wilks' $\lambda=.942 ; \mathrm{F}=34.853, \mathrm{p}<.05=.001$ ); sci (Wilks' $\lambda=.942 ; \mathrm{F}=34.833, \mathrm{p}<.05=.001$ ); mec (Wilks' $\lambda=.940 ; \mathrm{F}=29.775, \mathrm{p}<.05=.001$ ); and nat (Wilks' $\lambda=.939, F=26.14, p<.05=.001$ ). This combination of predictors (AAv, AAnv, bus, phy, sci, mec, and nat) only accounted for $\left(\mathrm{r}^{2}=.247\right)$ or $6.10 \%$ of the variability in predicted group membership (persistent, non-persistent).

Overall, this function accurately classified $65.6 \%$ of the students as persistent or non-persistent. Table 3 presents the overall discriminant function analysis rate for $A A$ and $O I A$. 
Table 3. Discriminant Function Analysis Using Occupational Interest Aptitudes and Academic Aptitudes in Combination as Predictors of Academic Persistence

\begin{tabular}{lcccccc}
\hline $\begin{array}{l}\text { Academic Aptitudes and } \\
\text { Occupational Interest Aptitudes }\end{array}$ & Wilks' $\lambda$ & $X^{2}$ & Sig. & Con $r$ & $r^{2}$ & $\begin{array}{l}\text { Accuracy } \\
\text { Rate }\end{array}$ \\
\hline Verbal & & & & & & \\
Non-verbal & & & & & & \\
Business Detail & .939 & 177.444 & .001 & .247 & $6.10 \%$ & $65.6 \%$ \\
Physical-Performing & & & & & & \\
Scientific & & & & & & \\
Mechanical & & & & & & \\
Natural & & & & & & \\
\hline
\end{tabular}

Level of significance $=.05$ alpha

Findings of this study provide evidence to reject the null hypothesis that AA and OIA in combination do not predict AP. When predictor variables were combined, a new set of predictor variables were found. Findings of this study are quite similar to that of Leuwerke et al. (2004). They found that occupational or vocational interest and academic variables (math achievement scores), in combination, predicted retention of engineering majors. In addition, AA and OIA as significant predictors of AP are consistent with Tinto's theory (as cited in Andres \& Carpenter, 1997; Braxton, 2000). Tinto's theory identified individual attributes to influence students' initial goal commitment and institutional commitment, which are linked to students' academic integration and, eventually, persistence. That is, students may or may not be fully integrated socially and academically because of mismatch or incongruence between one's aptitudes and course major. Findings also lend support to Pascarella's theory of academic persistence (as cited in Andres \& Carpenter, 1997), which identified aptitudes and interests as among the many student background characteristics that operate through or influence other factors such as institutional factors, college experiences, informal contact with faculty, educational outcomes, and eventually on persistence or withdrawal decisions of students.

Moreover, findings in this study suggest that academic aptitude and occupational interest aptitude in combination predict better than AA or OIA alone. Results indicated an increase in the predictive value of the two predictor variables in predicting AP when combined with an overall hit rate of $65.6 \%$. Nonetheless, though an increase in the ability to predict AP was indicated by combining AA and OIA variables, only $6.10 \%$ of the predicted group membership's variance can be attributed to those variables. This means that some factors may have contributed to students' academic persistence, which remained unaccounted for by this study.

\subsection{Contributing Factors to Academic Persistence}

Three themes were generated from the focus group discussion to have contributed to students' academic persistence. These themes are:

Theme 1: Competence and Motivation: This refers to students' academic abilities and skills, and the internal and external motivating factors which drive them to become persistent or non-persistent. This includes factors such as students' interest on the course, grade, personal aspirations, family and social expectations, career opportunities, and family responsibility.

Theme 2: Attitude and effort: This refers to students' values, the outlook in life, and strategies that they have, which made them overcome obstacles and become persistent in their studies. This includes being optimistic about their experiences, having the determination to succeed, having self-discipline and self-care, resourcefulness and frugality, time-management, and study habit.

Theme 3: Support and involvement: This refers to the financial and emotional support and involvement of the family or family members, peers, and institution which students believed influence their persistence in school. 


\section{CONCLUSIONS AND RECOMMENDATIONS}

\subsection{Conclusions}

There was enough evidence to reject the null hypothesis that academic aptitudes do not predict academic persistence. Verbal and non-verbal academic aptitudes significantly predicted academic persistence. On the other hand, occupational interest aptitudes business detail, physical-performing, scientific, industrial, and accommodating significantly predicted academic persistence.

Moreover, there was enough evidence to reject the null hypothesis that academic aptitudes and occupational interest aptitudes in combination do not predict academic persistence. Academic persistence was significantly predicted by $\mathrm{AA}$ and OIA: verbal, non-verbal, business, physical-performing, scientific, mechanical, and natural subscales.

\subsection{Recommendations}

Results showed that academic aptitudes and occupational aptitudes can only account for six percent of the dependent variable academic persistence; this indicates that other variables must be considered in determining the students who are at risk of not persisting. It is recommended that variables that emerged in the focus group discussion be further explored and tested for their ability to predict academic persistence so as to increase the predictive ability of the model generated in this study, and improve the hit rate in classifying group membership. Results of these studies could be the basis for an attrition intervention program.

During the focus-group discussion, only persistent students participated. It is recommended that a parallel study among non-persistent students be conducted in order to validate and further explore the themes that have been generated in this study.

Also, this study was conducted in a privately owned non-sectarian university; hence, findings cannot be generalized with public universities likewise with sectarian universities. It is recommend that this study be replicated in public or sectarian higher learning institutions.

\section{REFERENCE LIST}

Allen, K., \& Robins, S. (2008). Prediction of College Major Persistence Based on Vocational Interests, Academic Preparation, and First-Year Academic Performance. Research in Higher Education, 49, 6279. doi:10.1007/s11162-007-9064-5

Andres, L., \& Carpenter, S. (1997) Today's Higher Education Students: Issues of Admission, Retention, Transfer, and Attrition in Relation to Changing Student Demographics. The British Columbia Council on Admissions and Transfer. Retrieved from http://www.bccat.bc.ca/pubs/today.pdf

Braxton, J., (2002). Introduction to Special Issue: Using Theory and Research to Improve College Student Retention. Journal of College Student Retention, 3 (1), 1, 2. Retrieved from Proquest database. (609488751).

Brown, S., Lent, R., \& Larkin, K. (1989). Self-efficacy as a moderator of scholastic aptitude-academic performance relationships. Journal of Vocational Behavior, 35 (1), 64-75.

Burton, N., \& Ramist, L. (2001). Predicting Success in College: SAT® Studies of Classes graduating Since 1980. College Entrance Examination Board. New York. Retrieved from http://professionals.collegeboard.com/profdownload/pdf/rdreport200_3919.pdf

Caison, A. (2005). Determinants Of Systemic Retention: Implications For Improving Retention Practice In Higher Education. J. College Student Retention, 6(4) 425-441. Retrieved from Proquest database. (899834131)

Chamberlain, T., Catano, V., \& Cunningham, D. (2005). Personality as a Predictor of Professional Behavior in Dental School: Comparisons with Dental Practitioners. Journal of Dental Education, 69 (11), 12221237. Retrieved from http://www.jdentaled.org/content/69/11/1222.full

Cornwell, C., Mustards, D., \& Pary, J. (2008). How Does the New SAT Predict Academic Achievement in 
College? Retrieved from http://www.terry.uga.edu/ mustard/New\%20SAT.pdf

Daugherty, T., \& Lane, E. (1999). A longitudinal study of academic and social predictors of college attrition. Social Behavior and Personality

Feldman, K., Smart, J., \& Ethington, C. (1999). Major field and person-environment fit: Using Holland's theory to study change and Stability of College Students. The Journal of Higher Education, 70 (6), 642. Retrieved from http://findarticles.com/p/articles/mi_hb172/is_6_70/ai_n28743824/

French, B., Immekus, C., \& Oakes, W. (2003). A Structural Model of Engineering Students Success. ASEE/IEEE Frontiers in Education Conference. Retrieved from http://fieconference.org/fie2003/papers/1489.pdf

Goradia, T., \& Bugarcic, A. (2019). Exploration and evaluation of the tools used to identify first year at-risk students in health science courses: A systematic review. Advances in Integrative Medicine, 6(4), 143150.

Hess, F., Schneider, M., Carey, K., \& Kelly, A., (2009. DIPLOMAS AND DROPOUTS Which Colleges Actually Graduate Their Students (and Which Don't). A Project of the American Enterprise Institute. Retrieved from http://www.aei.org/docLib/Diplomas\%20and\%20Dropouts\%20final.pdf

Higgins, B. (2005). Strategies for Lowering Attrition Rates and Raising NCLEX-RN Pass Rates Journal of Nursing Education. 44 (12), 541

Hogan, R., \& Blake, R. (1999). John Holland's vocational typology and personality theory. Journal of Vocational Behavior, 55(1), 41-56.

Horn, L. (2006). Placing College Graduation Rates in Context: How 4-Year College Graduation Rates Vary With Selectivity and the Size of Low-Income Enrollment (NCES 2007-161). U.S. Department of Education. Washington, DC: National Center for Education Statistics. Retrieved from http://nces.ed.gov/pubs2007/2007161.pdf

Kahn, J. H., Nauta, M. M., Gailbreath, R. D., Tipps, J., \& Chartrand, J. M. (2002). The utility of career and personality assessment in predicting academic progress. Journal of Career Assessment, 10(1), 3-23.

Kobal, A., Kunze, K. R., \& Wrightstone, J. W. (1984). Academic aptitude test. Ocorn National Aptitude Test Manual of Direction

Leuwerke, W., Robbins, S., Sawyer, R., Hoyland, M. (2004). Predicting Engineering Major Status From Mathematics Achievement and Interest Congruence. Journal of Career Assessment, 12 (2), 135-149. doi: 10.1177/1069072703257756. Abstract Retrieved from http://jca.sagepub.com/content/12/2/135.

Macklem, G. L. (1990). Measuring aptitude. Practical Assessment, Research, and Evaluation, 2(1), 5.

Manila Bulletin. (2012, December 4).College Education for Poor Students. Retrieved April 25, 2014 from https://ph.news.yahoo.com

Metz, G. (2004). Challenge and Changes to Tinto's Persistence Theory: A Historical Review. Journal of College Student Retention, 6 (2), 191-207. Retrieved from Proquest database. (858406801).

Metz, G. W. (2002). Challenges and Changes to Tinto's Persistence Theory.

Navarro, R. L., Flores, L. Y., Legerski, J. P., Brionez, J., May, S. F., Suh, H. N., ... \& Hunt, H. K. (2019). Social cognitive predictors of engineering students' academic persistence intentions, satisfaction, and engagement. Journal of counseling psychology, 66(2), 170.

Newton, S., \& Moore, G. (2009). Use of Aptitude to Understand Bachelor of Science in Nursing Student Attrition and Readiness for the National Council Licensure Examination. Journal of Professional Nursing, 25 ( 5), 273

Newton, S., Smith, L., Moore, G., Magnan, M. (2007). Predicting early academic achievement in a baccalaureate nursing program. Journal of Professional Nursing, 23(3), 144-9.

Palmer, J. (2008). The Relationship Between Motivational Profiles And Admission Grade Point Scores To First Semester Attrition In An Associate Degree Nursing (Adn) Program. A Dissertation Presented in Partial Fulfillment Of the Requirements for the Degree Doctor of Philosophy, Capella University. Retrieved from Proquest Dissertations and Thesis. (3310901).

Parker, R. (1991). Occupational Aptitude Survey and Interest Schedule. Occupational Aptitude Survey and 
Interest Schedule Examiner's Manual ( 2nd ed).

Ragosta, M., Braun, H., \& Kaplan, B. (1991). Performance and Persistence A Validity Study of the SAT for Students Disabilities. College Board Report No. 91-3 ETS RR No. 91-41. College Entrance Examination Board, New York. Retrieved from http://professionals.collegeboard.com/profdownload/pdf/RR\%2091-3.PDF

Ridgell, S., \& Lounsbury, J. (2004). Predicting Academic Success: General Intelligence, "Big Five" Personality. College Student Journal, 38 (4). Retrieved from http://findarticles.com/p/articles/mi_m0FCR/is_4_38/ai_n9770166/pg_5/

Robertson, L., \& Taylor, C. (2009). Student Persistence in the Human Sciences: Freshman to Sophomore Year. Journal of Family and Consumer Sciences, 101( 1), 36

Spokane, A. R., Luchetta, E. J., \& Richwine, M. H. (2002). Holland's theory of personalities in work environments. Career choice and development, 4(2002), 373-426.

Stewart, S., Lim, D. H., \& Kim, J. (2015). Factors influencing college persistence for first-time students. Journal of Developmental Education, 12-20.

Stickney, M. (2008). Factors Affecting Practical Nursing Student Attrition. Journal of Nursing Education, 47(9), 422.

Tinto, V., \& Pusser, B. (2006). Moving from theory to action: Building a model of institutional action for student success. National Postsecondary Education Cooperative, 1-51.

Tinto, V., \& Pussher, B. (2006). Moving From Theory to Action: Building a Model of Institutional Action for Student Success. National Postsecondary Education Cooperative. Washington D.C: U.S. Department of Education. Retrieved from http://nces.ed.gov/npec/pdf/Tinto_Pusser_ExecSumm.pdf

Titus, V. (2004). An Examination of the Influence of Institutional Context on Student Persistence at 4-Year Colleges and Universities: A Multilevel Approach Marvin A Titus. Research in Higher Education, 45(7), 673

Tracy, T., \& Robins, S. (2006). The interest-major congruence and college success relation: A longitudinal study. Journal of Vocational Behavior, 69 (1), 64

Wallace, P. (2004). WHERE to The Philippines? (Or Does The Philippines Have A Chance?). The Wallace Report, p.15. Retrieved from http://www.dataphil.com/special/whither.pdf

Zwick, R., \& Sklar, J. (2005). Predicting College Grades and Degree Completion Using High School Grades and SAT Scores: The Role of Student Ethnicity and First Language American Educational Research Journal, 42 (3), 439-464. 